\title{
A Study of Fuel Cell Scheduling Effect on Local Energy Markets with Heterogeneous Renewable Sources ${ }^{\dagger}$
}

\author{
Borislava Spasova ${ }^{1,2, *}$, Daisuke Kawamoto ${ }^{1}$ and Yoshiyasu Takefuji ${ }^{2}$ (i) \\ 1 Sony Computer Science Laboratories Inc., 3-14-13 Higashigotanda, Tokyo 141-0022, Japan; \\ kawamoto@csl.sony.co.jp \\ 2 Graduate School of Media and Governance, Keio University, 5322 Endo, Fujisawa, \\ Kanagawa 252-0882, Japan; takefuji@sfc.keio.ac.jp \\ * Correspondence: b.spasova@gmail.com; Tel.:+81-8044-0941-44 \\ + This paper is an extended version of our paper published in 2018 IEEE International Conference on \\ Environment and Electrical Engineering and 2018 Industrial and Commercial Power Systems, Europe, \\ Palermo, Italy, 12-15 June 2018.
}

Received: 15 January 2019; Accepted: 28 February 2019; Published: 5 March 2019

\begin{abstract}
The study presented in this paper aims to show the impact of introducing a priority-based internal power flow management system on the local energy market of prosumers with solar panels, fuels cells and batteries. The community used for the study is based on the Open Energy Systems (OES), in which 19 autonomous subsystems, equipped with batteries, solar panels and AC grid connection are interconnected via a DC power bus. For the simulation purposes, fuel cell, modeled after Ene-Farm, is added to the original configuration. Each standalone system has internal, priority-based, agent, capable of scheduling the operating hours of the fuels cell to maximize the utilization of the generation and minimize curtailment. The energy market is based on a simplified version of the Zaraba, a continuous double auction algorithm used by the Japanese Stock Exchange, in which prosumer can submit a bid for a future timeslot. The preliminary numerical evaluation is based on the results from several simulations using different versions of the internal management system.
\end{abstract}

Keywords: energy trading; microgrid; bidding strategy; heterogenous power sources; fuel cell

\section{Introduction}

This paper is an extension of the work titled "Energy exchange strategy for local energy markets with heterogeneous renewable sources", originally presented in the 2018 IEEE International Conference on Environment and Electrical Engineering and 2018 Industrial and Commercial Power Systems [1] in Palermo, Italy.

In recent years, the dropping prices for energy storage and Feed-In Tariffs (FIT) [2] has led to widespread adoption of solar energy and has opened up possibilities for prosumers to play an active role in the energy markets. In addition, with the improvement of technology and reducing of the cost for Distributed Renewable Resources (DER), the on-site energy sources such as fuel cells, wind turbines, etc., are becoming more popular with consumers [3]. However, the current nature of both the grid infrastructure and the electricity markets is preventing residential customers from participating in the said markets and from taking full advantage of cheaper renewables. This calls for a new approach to market design that reflects both the locality of the energy exchange and the increased heterogeneity of the microgrids as well as for the development of more prosumer oriented exchange strategies. 
The original paper [1] presented a study of the effects of the installation of hydrogen fuel cells in a proposed local energy market with renewables and batteries. For the purpose of the study, a prototype, based on existing microgrid Open Energy Systems (OES) [4], located in Okinawa, Japan, was developed, mimicking closely the operation of the baseline system. OES consists of autonomous subsystems, equipped with solar panels, batteries and loads and interconnected via dc power bus. Although the existing system had well defined exchange algorithm [5] which allows energy exchanges between all of the connected subsystems, it offered no financial rewards. The developed prototype aimed to change that by creating a solution for prosumer oriented, market-based trading which can provide possibilities for cost reduction to the prosumers, enable them to take better advantage of the renewables and make them active participants in the local energy market. Such approach increases the self-sufficiency of the community itself, makes it more sustainable and expands the possibility for decentralized energy exchange.

The market was designed in the form of double auction, where a prosumer can submit a bid for future timeslot with a given amount and price for electricity. Both the amount and the price were determined by the individual prosumer's Exchange Strategy, which is based on the State of Charge (SoC) of the available battery. The proposed solution consisted of three main components: a priority-based internal agent, responsible for the power flow management; a bidding agent, used for evaluating the future needs for electricity; and an external agent, tasked with managing the local market. In order to test the SoC-based exchange strategy, a hydrogen fuel cell was added to the original configuration of the subsystems. The fuel cell is of a particular interest to the authors of this paper because of its ability to provide stable generation, which unlike the fluctuating output of the solar panels, can be used to cover the base load of a household thus expanding the possibilities for building self-sufficient, off-grid communities. In the performed tests the internal, priority-based, agent was found to lack complexity and more specifically the functionality for scheduling the operating hours of the fuel cell. This was viewed as one of the factors that contributed to the results presented in the paper from 2018 IEEE EEEIC/I\&CPS [1].

Following the results of the study, a scheduling component, which offers scheduling of the operating hours of the fuel cells based on the prosumer's preferences, was added to the internal power flow management agent. This manuscript presents a study of the effects of the implemented changes on the local market and on the individual prosumer. The evaluation is done by comparing the results from the original paper with the results produced by the upgraded prototype. Unlike the previous paper, where the analysis was performed for 1 day, this one extends the observed period to 1 week, including the date, previously analyzed.

Section 2 of this paper will provide a deeper understanding of the current state of the existing P2P energy trading solutions and will serve as an introduction to the basic concepts used in the development of the solution, which is the subject of this research. Section 3 will give an overview of the prototype's design and the concrete implementation which is used for the quantitative evaluation. Finally, Section 4 will focus on the analysis of the simulations' results followed by final remarks and discussion of future works.

\section{Research Background}

This paragraph will introduce existing solutions for energy exchange between interconnected subsystems. Asimakopoulou [6] and Wang [7] both proposed strategies for interconnected microgrids to interact with the main grid, with the former proposing a Leader-Follower strategy for energy management of Multi-Microgrids by focusing on bilateral contracts between microgrids and a large production unit, and the later introducing a control strategy for networked microgrids and distribution systems. Matamoros and Gregoratti [8,9] developed an optimization framework for a distributed energy trading algorithm between islanded microgrids. Although they are among the first to propose direct trading between microgrids, their solution do not separate the microgrids' internal strategy from the exchange strategy which limits possibilities of implementing self-interest-based internal strategies. 
Wang [10-12] suggested a two-layered optimization method that separates internal and external strategy, and therefore allows self-interested microgrids to collaborate. Other papers $[13,14]$ use concepts of Game Theory for the trading algorithm, while Nunna [15] came up with an multi-agent approach for power trading between microgrids using demand response and distributed storage.

Dimeas' paper [16] proposed a multiagent system (MAS) approach of Buyers and Sellers making Bids for EnergyPackages according to GridPrices. Other papers also discussed this kind of approaches [17-19] but mainly from a theoretical point of view without physical prototype.

The solution, presented here, adopts Wang's approach, but unlike the majority of the research in the area, it focuses on localized trading between the members of one microgrid. The developed prototype implements a system, which provides clear separation between the internal strategy for energy management and the trading, implemented with the external strategy. This manages to not only address both the lack of incentive and the decision coupling issue, but also allows for the development of more self-interest-based energy exchange strategies customized to the individual prosumer's needs. The internal strategy is tasked with the power flow management of the individual subsystem and the analysis of the subsystem status used to determine the willingness for buying or selling electricity. It is implemented by the priority-based internal agent and the bidding agent, respectfully. The external strategy implements the actual trading algorithm.

\section{Design and Implementation}

The prototype, presented here, uses as a baseline system the Open Energy Systems (OES), a real world microgrid in Okinawa, Japan. This section will provide an overview of the basic premises and concrete algorithms used in the development of the proposed solution as well as brief description of the OES system.

\subsection{Microgrid Architecture}

The OES is a fully decentralized microgrid in which autonomous subsystems are interconnected via a DC power bus, using a direct current (dc) procedure for exchange, combined with pure peer-to-peer (P2P) communication infrastructure and exchange algorithm [5]. The OES community is comprised of 19 houses, equipped with dc nanogrid, batteries, solar panels and loads, which represents a basic standalone subsystem. Each subsystem also has a connection the standard electrical (AC) grid, which is used as an auxiliary power supply. More detailed description of this type of system can be found in the referenced papers $[4,20]$.

To study the impact of the installation of stable energy source on the prosumer and the market, a fuel cell is added to the configuration of each standalone subsystem. The fuel cell in question is modelled after Ene-farm, a hydrogen fuel cell for home use, that has been gaining popularity in Japan. Ene-Farm is an energy system that can extract hydrogen from both natural gas, supplied though underground pipes in major cities, and propane gas (LPG), supplied to a residence via external tanks, secured to the outer walls. The hydrogen is then used in combination with ambient oxygen to generate electrical power and simultaneously to capture the residual heat which in turn is used to heat up water. Ene-Farm was chosen here for both its wide spread use and its high efficiency ratio.

The extended topology of the observed microgrid can be seen on Figure 1. 


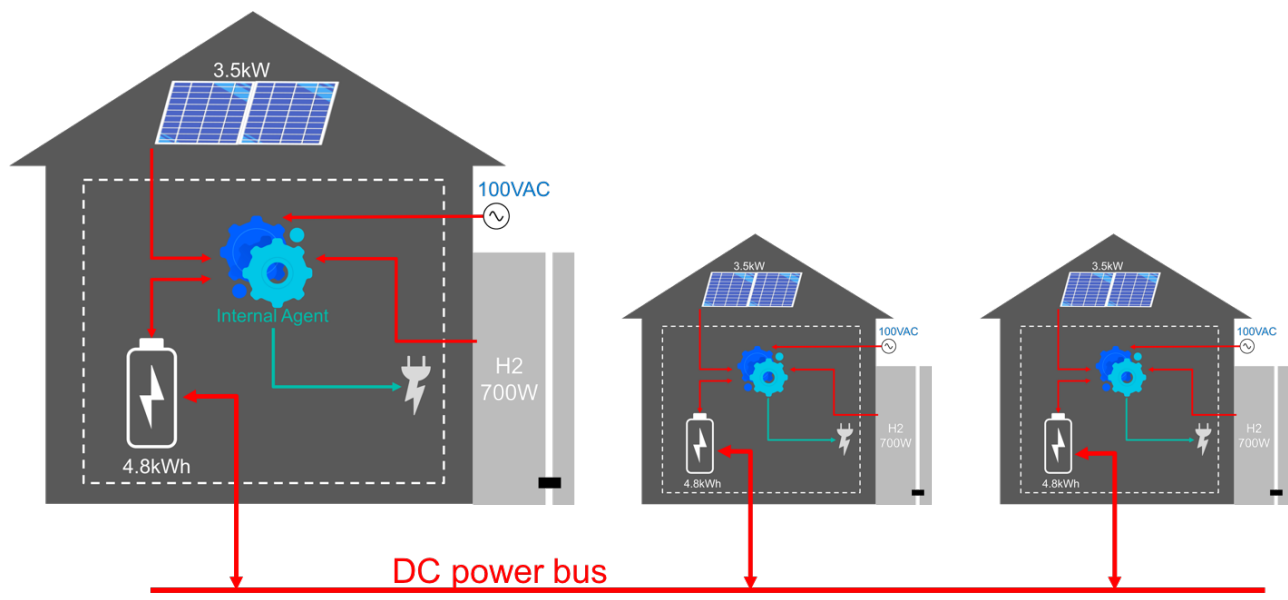

Figure 1. Home system configuration and microgrid topology of the baseline microgrid.

\subsection{Design Assumptions and Limitations}

During the development of the prototype several assumptions were taken. In this manuscript only the base premises are given For more detailed list, please refer to the cited paper [1].

1. All losses, including conversion and transmission losses, are neglected;

2. Each subsystem has a battery, use for absorbing the network imbalances;

3. It is assumed that the data, provided by the power meters and the controllers, can be trusted;

4. The DC line capacity, in this case $2.5 \mathrm{kw}$, is the same for all subsystems;

5. Due to the location of the study, Japanese yen is chosen as main currency for the financial transactions;

6. The utility grid is not use for charging the battery;

7. There is no Feed-in to the utility grid

\subsection{Prototype Design}

The following paragraphs will give a short description of the internal and externals strategies, focusing on the priority-based internal agent component of the former. For more information about the chosen algorithms, please refer to the cited paper [1].

\subsubsection{Internal Strategy}

As stated above, the internal strategy is responsible for the power flow management of the individual subsystem and for the analysis of the subsystem current status used for determining the willingness for energy trading. The internal strategy has two main components, a priority-based internal agent and bidding agent, presented in the following paragraphs.

\section{Priority-Based Internal Agent}

The internal agent is responsible for scheduling the power flows to and from the configured modules. It is designed for standalone house, equipped with batteries, energy sources and loads. The central idea in the design of the system is to offer choice to the prosumer for the number and the type of power sources they wish to install in their home. The configurations allow for the installation of one or more power sources such as wind turbines, fuel cells, solar panels, AC grid, etc. In the system used on the original paper [1], the only requirement was for each connected source to be assigned clear priority, based on the estimated energy price and the cost for curtailment. Usually power sources with expensive curtailment, like fuel cells, are given higher priority even though the cost for electricity for solar energy is lower. In the case of this prototype the priority is as follows: fuel cell output, 
when available; solar generation; battery; utility grid. In this system, the battery plays a dual role as both a power source and a load.

For this paper, the functionality of the internal agent has been expanded by adding operation scheduling for power sources with constant output, in this case the fuel cell. The new function allows for the scheduling condition to be customized by the users to fit their needs. In the case of the Ene-Farm, $30 \mathrm{~min}$ are required for both shut down and startup of the fuel cell therefore the default conditions are set based on the solar generation output and the SoC of the battery to take into account the future state of the system. Figure 2 shows the basic workflow of the priority-based internal agent with the defined configuration.

\section{Step 1: Schedule fuel cell status}

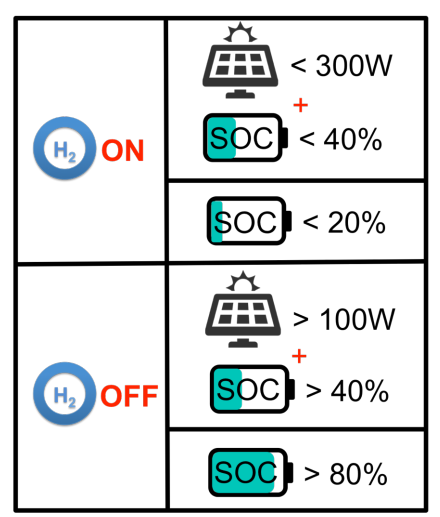

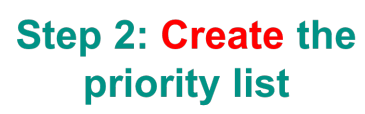

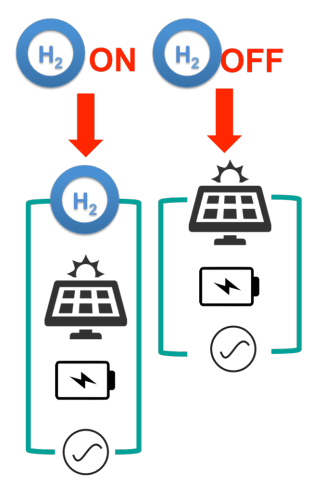

\section{Step 3: Manage power flow}

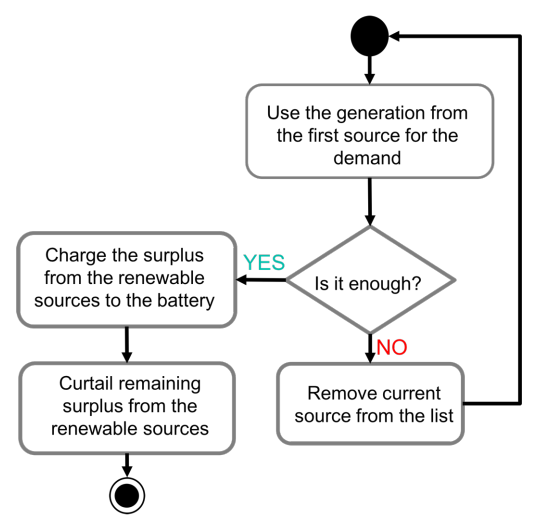

Figure 2. Scheduling conditions and simplified workflow of the internal agent.

Bidding Agent

Similar to the internal agent described above, an instance of the bidding agent runs in each individual subsystem. It analyzes the individual subsystem's configuration, e.g., the installed modules such as batteries, solar, fuel cells, etc., their current consumption and generation to determine the present and future status of the subsystem, which is then used by a price function to determine the future need for electricity. The agent then translates that into an order bid for selling or buying electricity in future timeslots.

The paper uses the same bidding strategy as previous works [1]. As it can be seen on Figure 3, it used the State-of-charge $(\mathrm{SoC})$ of the battery to predict future need of electricity, in this case for the next $30 \mathrm{~min}$. The base amount, seen in Figure 3, refers to the minimum amount of electricity available for exchange, calculated as a function of the dc line capacity and the trading timeslot duration to avoid line congestion.

\begin{tabular}{|c|c|c|c|c|}
\hline \multirow{2}{*}{$\begin{array}{c}\text { Battery SoC } \\
(\%)\end{array}$} & \multicolumn{2}{|c|}{ Sell Bid } & \multicolumn{2}{c|}{ Buy Bid } \\
\hline$<=20$ & price (yen/kWh) & $\begin{array}{c}\text { amount(watt- } \\
\text { hour) }\end{array}$ & price (yen/kWh) & $\begin{array}{c}\text { amount(watt- } \\
\text { hour) }\end{array}$ \\
\hline $20-40$ & 30 & base & 25 & (base) $\times 4$ \\
\hline $40-60$ & 20 & (base) $\times 2$ & 10 & (base) $\times 3$ \\
\hline $60-80$ & 15 & (base) $\times 3$ & 5 & (base) $\times 2$ \\
\hline$>80$ & 10 & (base) $\times 4$ & & base \\
\hline
\end{tabular}

Figure 3. Bidding prices and amounts for State of Charge (SoC)-based bidding strategy. 


\subsubsection{External Strategy}

The external strategy represents the software implementation of the proposed electricity market. It uses simplified version of the Zaraba method, a continuous double auction algorithm used by the Japanese Stock Exchange to match existing bids, to manage agreed deals and to monitor financial transactions. Since it is real time trading, the bids for a given $30 \mathrm{~min}$ timeslot are matched on first-come first-served basis with the most advantageous counter bid being chosen each time as a counterpart. At the end of the timeslot the agreed deals are sent to the internal agent to perform the physical exchange and all the unmatched bids are invalidated.

\subsubsection{Virtual Wallet}

Each standalone system is provided virtual wallet, a small module, that keeps record of the electricity cost, the cost for charging the battery from the renewable sources and the cost/revenue from the energy trading with the other prosumers.

\section{Simulation Setup and Results}

The prototype, studied in this paper, is developed using Python 3.6 to provide software approximation of the power flow within the community and is loosely based on the OES Simulator [5]. The internal and the external strategies are implemented as described in the previous section and in previous works [1]. In this paper, only the ideal case is considered, meaning that hardware losses are neglected. This section will give information about the setup of the simulation and the configuration of the observed home systems as well as detailed analysis of the obtained results.

\subsection{Input Data and Configuration}

As in previous works [1], the simulation uses real data for the consumption and solar radiation for the year 2015, from a data set of 19 houses, part of OES in Okinawa, Japan. The data, recorded on site, has 10 minutes granularity. The duration of the contract's timeslot is set to $30 \mathrm{~min}$, which results in 48 trading timeslots per day.

1. Solar panels: area-20 $\mathrm{m}^{2}$; panel yield $-19 \%$; performance ratio-75\%; price for electricity-0 yen for $\mathrm{kWh}$. The initial investment in installation of the solar panels is ignored when estimating the price.

2. Fuel cell: output-700 watts, price for electricity -14 yen for $\mathrm{kWh}$. As in the case of the solar generation, the initial investment in the fuel cell is ignored and the price is solely based on the fuel used, in this case natural gas.

3. Utility grid connection: an auxiliary power source with no power limitations; price for electricity-30 yen for $\mathrm{kWh}$.

4. Battery: capacity-4.8 $\mathrm{kWh}$, initially charged at $50 \%$; price for electricity-calculated in the beginning of every iteration and it is based on price of the renewable power sources that has charged it in the previous cycle.

5. Wallet: initial amount-10,000 Japanese yen.

\subsection{Results}

In order to evaluate the added functionality presented in this paper, two simulations are performed, each using different priority-based internal agent as listed below:

1. Internal agent, described in the cited paper [1].

2. Internal agent, presented in this paper.

Real data, taken for the duration of 1 month, March 2015 from 19 houses, each configured as shown in the previous subsection, is used as a dataset for the performed simulations. For the purpose of the 
analysis only one week, from March 21st to March 28th, consisting of several sunny days, one partially cloudy day and one very cloudy day is chosen for more realistic results. Furthermore, to improve analysis, the daily consumption patterns of all 19 members of the OES community were examined. The consumers were divided into three main groups, based on their average daily consumption for the observed period and using the generated output from the fuel cell as a base indicator. The groups are as follows:

1. High consumers-daily average more than 700 watts;

2. Average consumers-daily average between 350 watts and 700 watts;

3. Low consumers-daily average less than 350 watts.

As it can be seen on Figure 4, more than $50 \%$ of the consumers fall into the second category, a trend that remained unchanged for the entire year 2015.

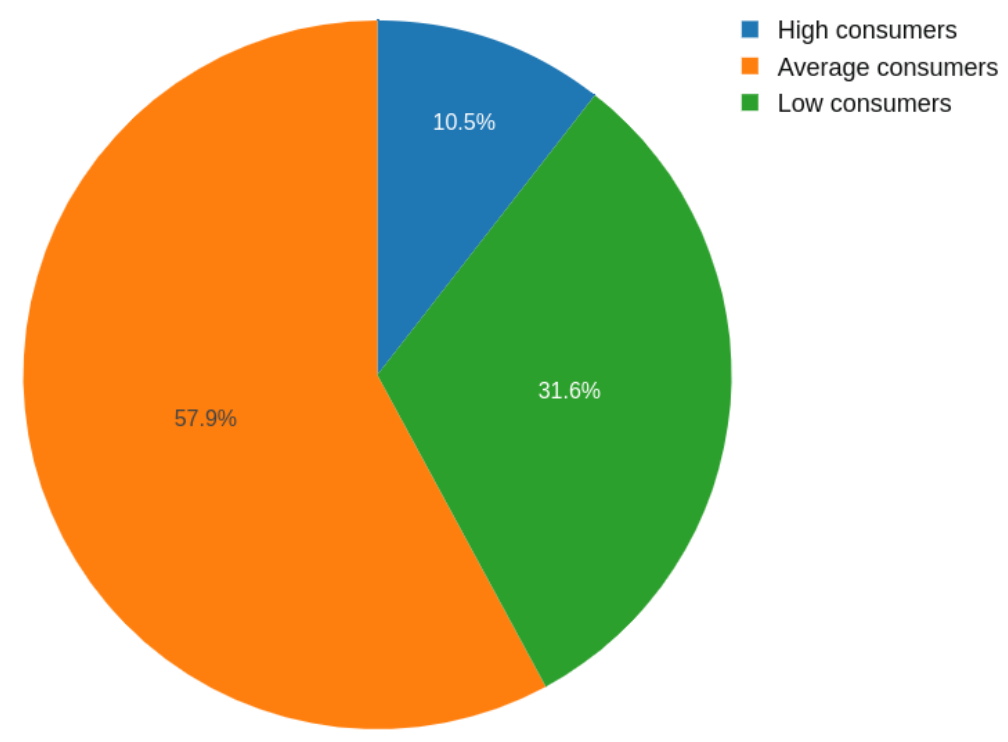

Figure 4. Types of energy consumers in the Open Energy Systems (OES) community.

The division of the community into the categories, listed above, proved to be a very effective way to study different types of consumers since all of the members in each category tend to exhibit similar behavior within an acceptable margin of error.

Detailed analysis of the power sources' usage for consumption for all 19 houses for the observed period shows that when the simple priority based agent is uded for the internal power flow management, all the houses are shown to rely heavily on the fuel cell generation. Due to low average levels of consumption, more than $99 \%$ of the consumption for consumers in the third category is covered by the fuel cell generation and less that $1 \%$ comes from the battery and the solar generation combined. This can be seen on Figure 5a. Since all subunits share the same configuration, it is reasonable to conclude that the members of this category are likely to have excessive curtailment from both the solar generation and the fuel cell output. In addition, they are likely to maintain constant high levels of willingness to sell energy, thus emulating the behavior of a producer of energy rather than a prosumer. 


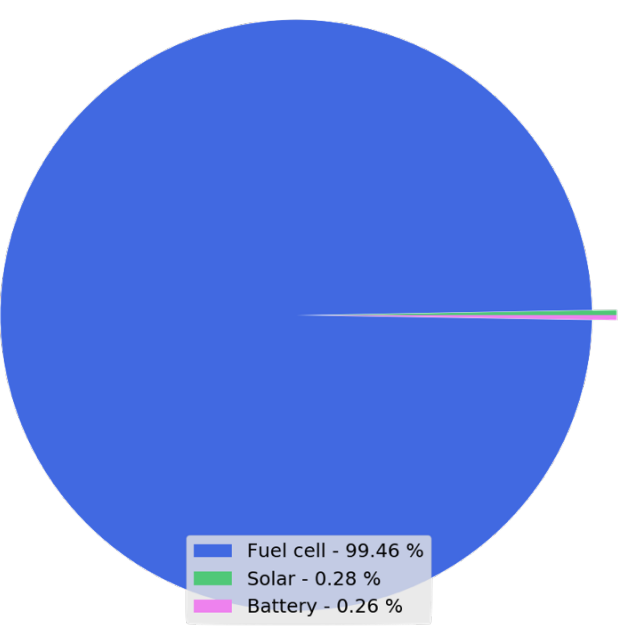

a)

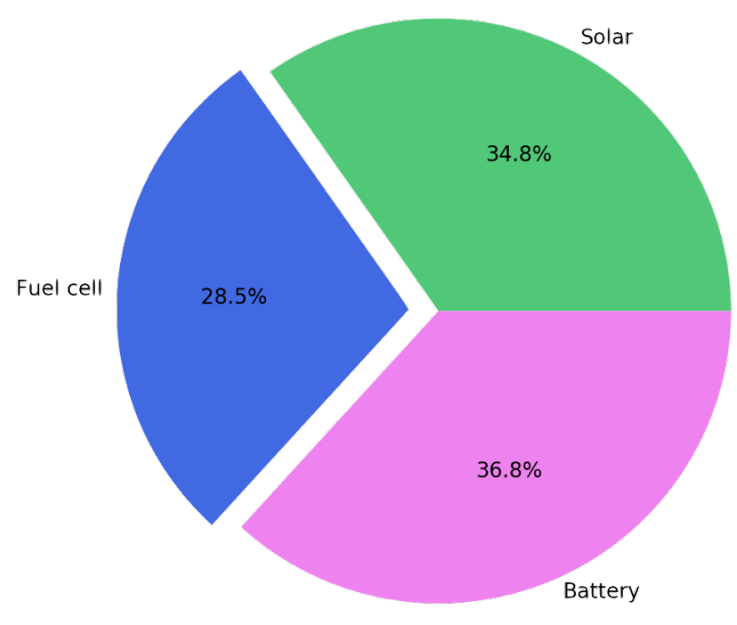

b)

Figure 5. Example of energy usage by power sources for low consumer with priority-based internal agent (a) without fuel cell scheduling function and (b) with added scheduling capabilities.

Unlike low customers, the prosumers in the other two categories exhibit similar behavior, as it can be seen in Figures $6 \mathrm{a}$ and $7 \mathrm{a}$. For the average consumers, between $80 \%$ and $85 \%$ of their consumption is covered by the fuel cell generation while for the high consumers that number decreases. The estimated $10 \%$ difference is covered by the battery while the solar usage remains relatively the same. Similar to the low consumers, the prosumers in these two categories have energy excess that is likely to be curtailed although not to the same extend. In addition, higher energy cost is observed for all prosumers due to the heavy usage of the fuel cell.

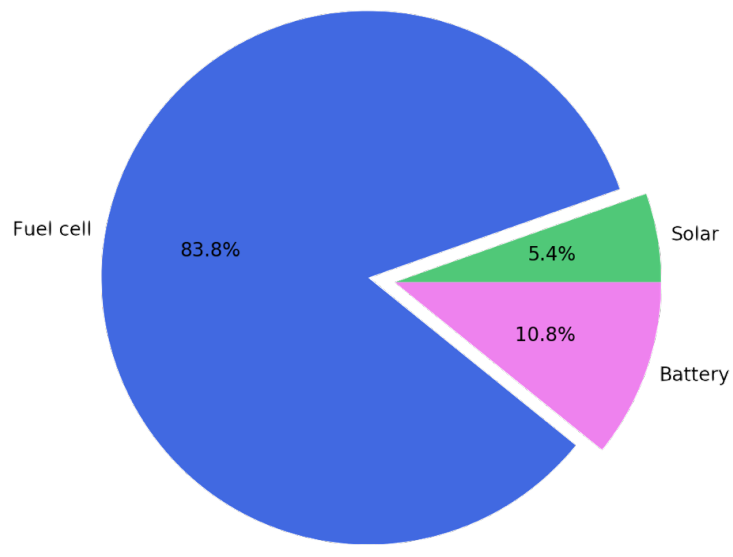

a)

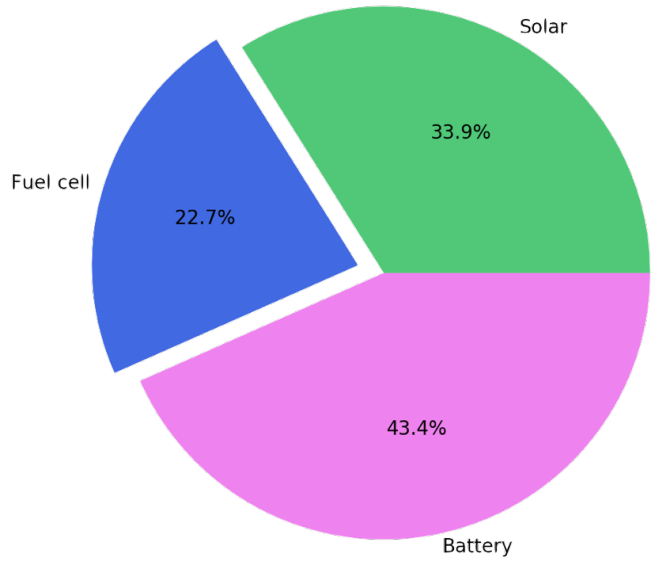

b)

Figure 6. Example of energy usage by power sources for average consumer with priority-based internal agent (a) without fuel cell scheduling function and (b) with added scheduling capabilities. 
As it can be seen on Figures $5 \mathrm{~b}, 6 \mathrm{~b}$ and $7 \mathrm{~b}$, introducing scheduling component to the priority-based internal agent changes drastically the previously observed patterns. The added control over the availability of the fuel cell output has forced the internal system to use the battery and the solar generation more, giving the three power sources almost equal shares in covering the consumption. The increased reliance on the solar coupled with the reduce usage of the fuel cell generation has resulted significant drop in the energy cost of between $45 \%$ and $53 \%$ for all members of the community.

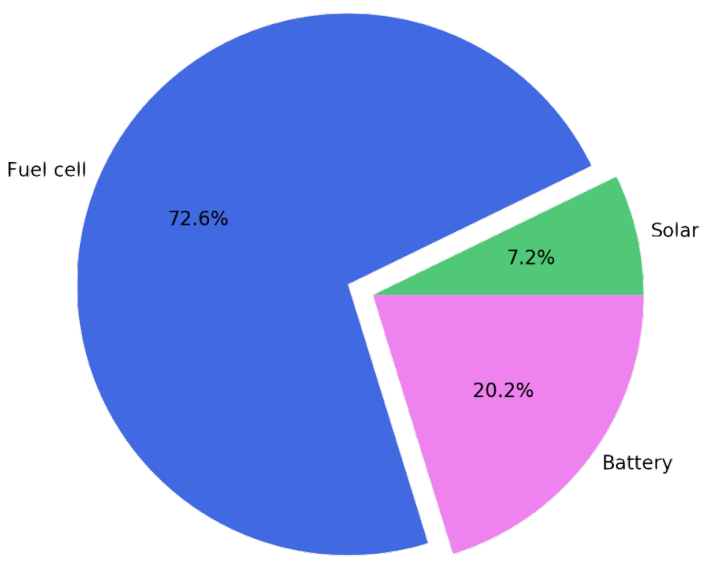

a)

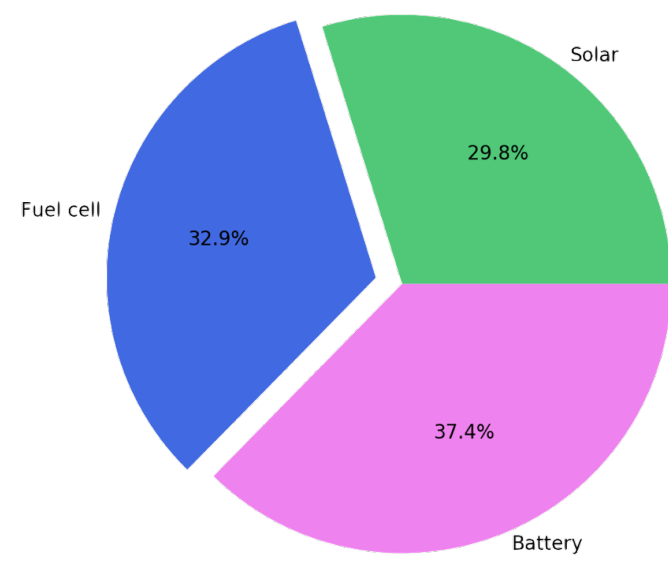

b)

Figure 7. Example of energy usage by power sources for high consumer with priority-based internal agent (a) without fuel cell scheduling function and (b) with added scheduling capabilities.

The findings, discussed above, are further confirmed by the observed curtailment in the two defined scenarios. Figure 8a shows the community curtailment in case 1 when the simplistic priority-based agent is used. The high levels of both solar and fuel cell curtailment has contributed to the higher cost for electricity due to the price for the fuel cell generation. The introduction of a scheduling component to the internal agent has resulted in the decrease in the solar curtailment and in the complete elimination of the curtailment from the fuel cell, which can be seen on Figure 8b. Thus, it can be concluded that the addition of the scheduling functionality reduces the energy cost, maximizes the utilization of the generation and minimizes the curtailment. Notably, in both cases, no energy was bought from the utility grid.

Further analysis of the financial transactions, obtained by the two simulations, has shown that in addition to the losses suffered due to the heavy use of the fuel cell, the prosumers using the the first internal agent were less competitive in the market. For the observed period only 116 deals were recorded in the case of the original agent, while 1269 deals were executed for the same duration using the upgraded version. As stated in other works [1], this is due to the SoC-based exchange strategy, used for the both examples. The outcome of the first simulation shows patterns similar to the ones previously observed [1] with high surplus of the generation resulting in constantly high SoC levels of more that $50 \%$, Figure $9 a$, which leads to decreased willingness to buy electricity and fewer deals. In comparison, the SoC levels shown on Figure $9 \mathrm{~b}$ resemble more patterns normally contributed to standalone systems, equipped with only solar panels. Unlike such configurations, in this case the SoC levels never reach $0 \%$. The more balanced SoC levels lead to an increased interest in trading throughout the 24-h time period and to more deals. This contributes to lowering the cost for electricity for all members of the community and even generates surplus of roughly 230 yen for the ones with lower consumption. 

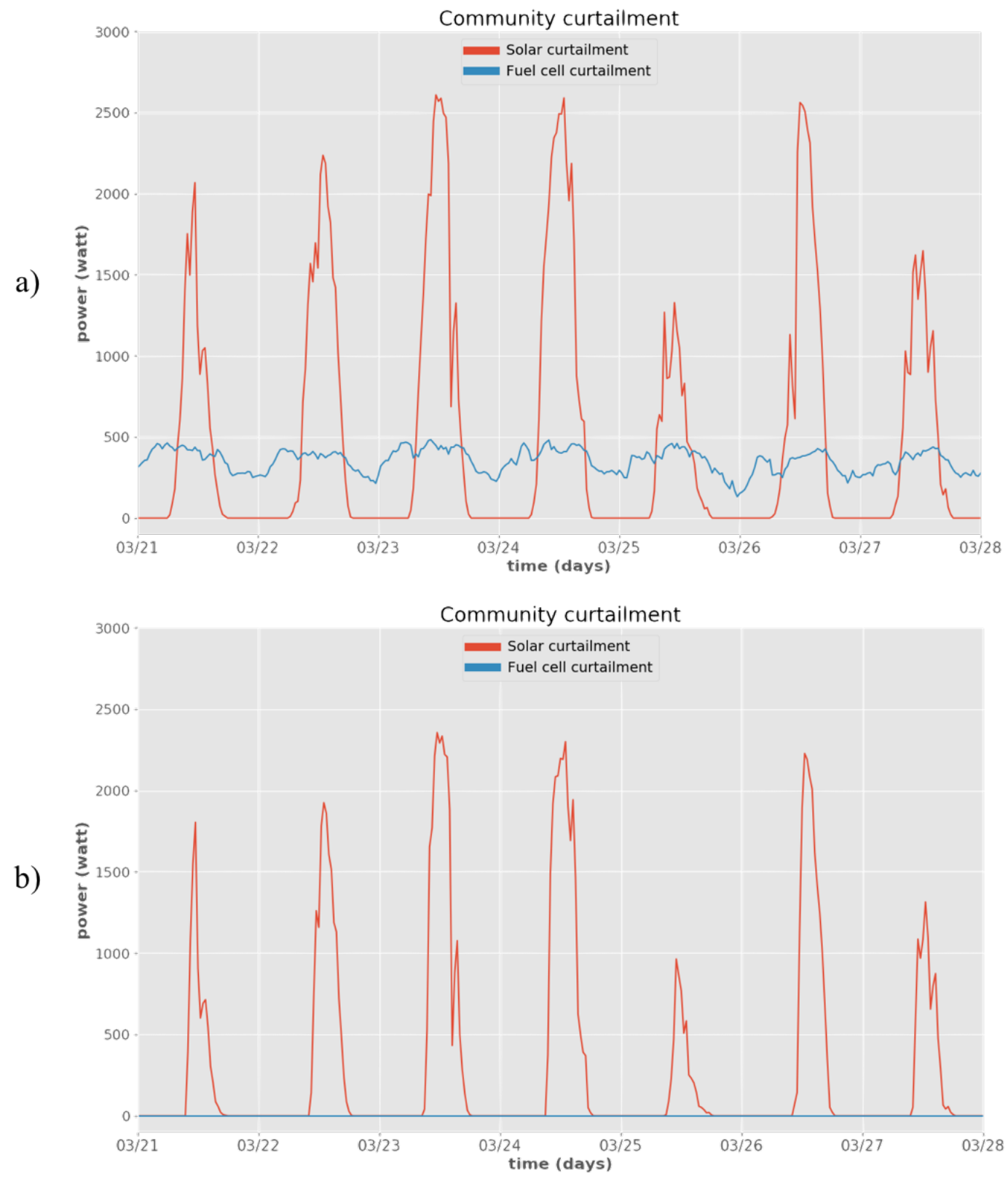

Figure 8. Average curtailment in community, comprised of standalone houses with solar panels and fuel cells, using priority-based internal agent (a) without fuel cell scheduling function and (b) with added scheduling capabilities.

Stabilizing the SoC levels has also effect on the the market price. In previous work [1], it was discovered that adding fuel cell to a community with solar panels and batteries leads to fixed market price of 10 yen for $\mathrm{kWh}$, which in addition to the diminished number of deals, reduces the financial incentive for the prosumer, Figure 10a. Adding scheduling capabilities to the priority agent has revitalized the market and moreover, due to the stable nature of the fuel cell generation, has established more predictable price patterns, Figure 10b, with prices high as expected during the night where the main power source is the fuel cell and low at midday when the solar generation is at its peak. 

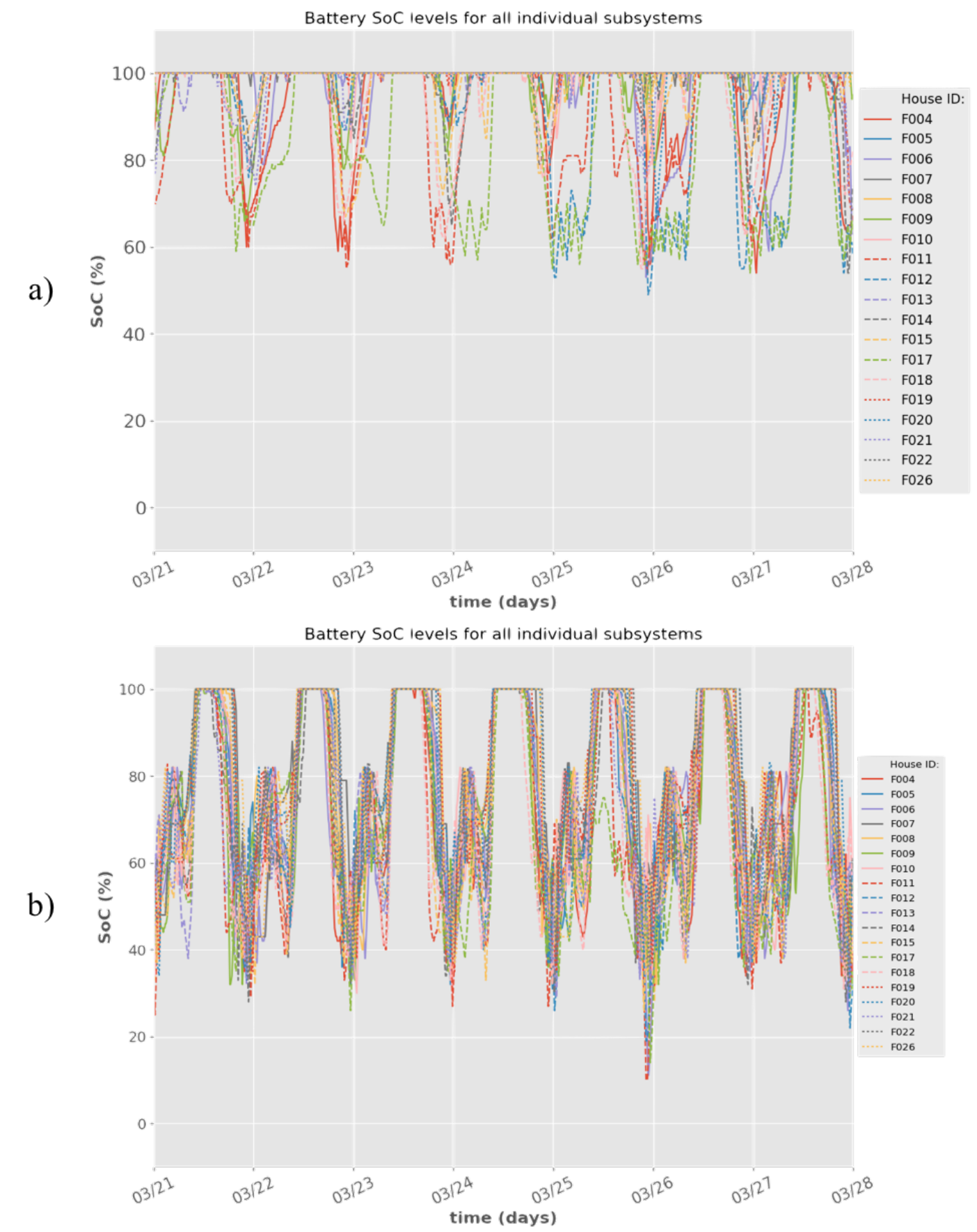

Figure 9. Battery SoC level of all standalone systems in the cases of using (a) priority-based internal without fuel cell scheduling function and (b) priority-based internal with added scheduling capabilities.

The priority-based agent, presented in this paper, has achieved its intended purpose of making prosumers with solar panels and fuel cell more competitive in the proposed market. It has succeeded in reducing curtailment and increasing the utilization of the renewable energy. Moreover, it has helped to stabilize the market price into a predictable pattern which opens the possibilities for future expansion of the bidding strategy. 

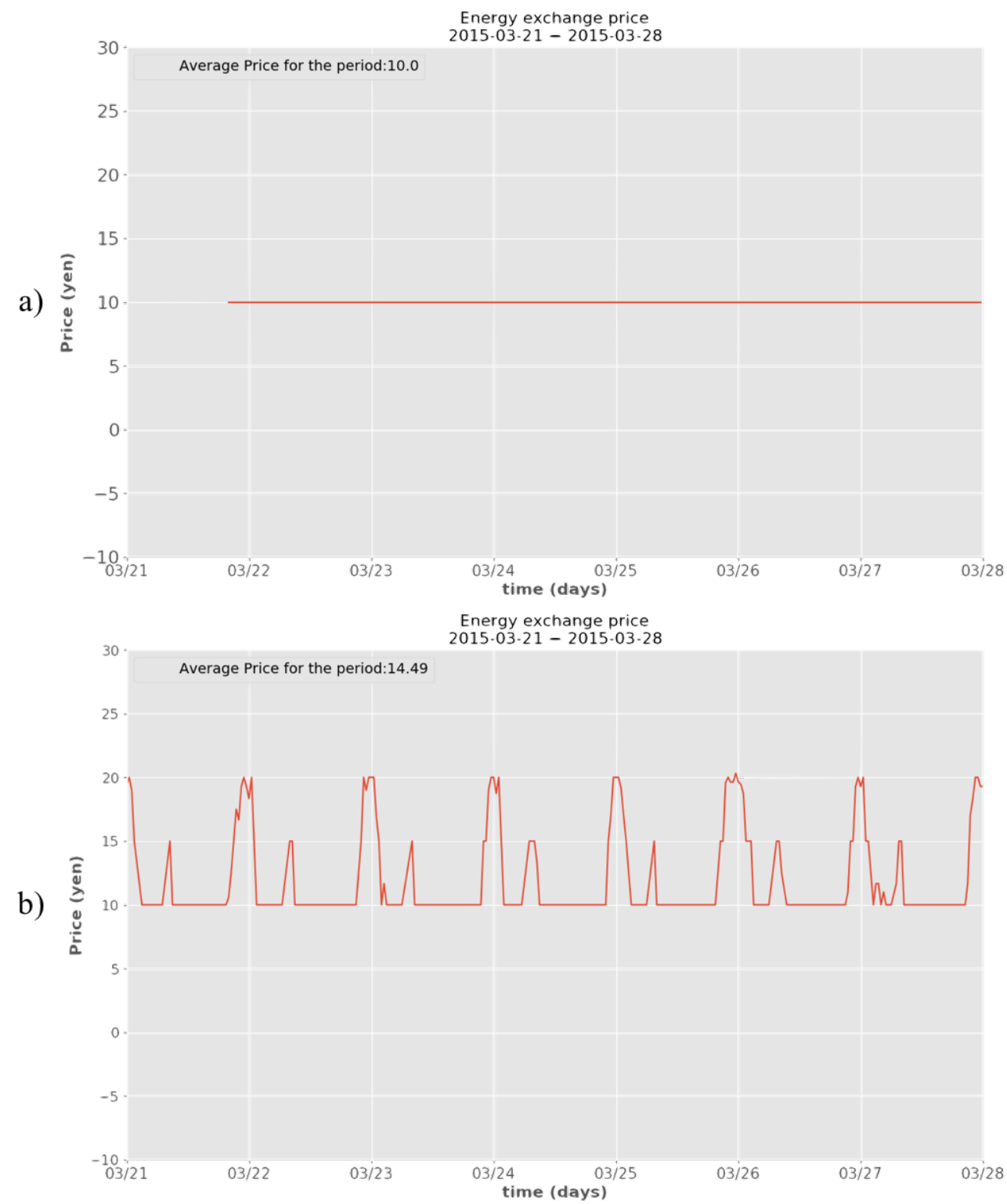

Figure 10. Market price within a community, comprised of standalone houses with solar panels and fuel cells, using priority-based internal agent (a) without fuel cell scheduling function and (b) with added scheduling capabilities.

\section{Discussion}

This study shows the impact of priority-based internal agent with added scheduling functionality, capable of controlling the operating hours of a power source with constant generation such as fuel cell. Python-based simulation, using real data from a full-scale microgrid, consisting of 19 houses, equipped with solar panels, fuel cells, batteries and AC grid connection, is used for evaluation. All the houses are connected via a dc power bus which allows them to exchange any excess energy with their neighbors, using the P2P exchange algorithm. A continuous double-auction algorithm, used by the Japanese Stock exchange, is used for the implementation of the trading platform. Similar to previous works [1] some simplifications are incorporated into prototype such as neglecting hardware losses, not taking into account the price of the electricity from the battery when calculating the bidding price, etc. Although the exact effects these assumption on the market are yet to be studied, it is expected that they will cause an increase in the market price. This topic is currently being investigated and will be a subject to future works. 
This paper focuses on the results of adding component capable of scheduling the operation of the fuel cell to the internal agent. This addition has greatly improved the performance of the internal agent in the case of standalone system with heterogeneous power sources by balancing the SOC levels of the battery and stabilized the market prices into more predictable 24-h patters. Still, it is the opinion of these authors that a more comprehensive bidding strategy is needed. The strategy should be locally optimized for each prosumer according to the predicted consumption patterns prosumer's preferred path, e.g., maximizing the profit, and maintaining a sustainable system, independent from the utility grid, etc., and should include future prediction for the generation patterns as well. Furthermore, with the wide spread of renewables and distributed renewable resources (DER), more diverse communities are likely to appear so further tests in the community with standalone systems with various configuration power sources can serve as a testing environment to achieve more realistic results which can be used to evaluate the market from the perspective of the customer [1].

Author Contributions: Writing—original draft preparation, software, simulations, investigations, visualization, B.S.; conceptualization, methodology, formal analysis, data curation, B.S. and D.K.; validation, resources, D.K.; supervision, writing-review and editing, D.K. and Y.T.

Funding: This research received no external funding.

Acknowledgments: The authors would like to express their gratitude to Okinawa Institute of Science and Technology and H.Kitano for the continuous support. Particular thanks go to A.Werth and M.Hoshino, who greatly contributed in forming these ideas. The authors wish also to thank the reviewers for their helpful and constructive comments.

Conflicts of Interest: The authors declare no conflict of interest.

\section{References}

1. Spasova, B.; Kawamoto, D.; Takefuji, Y. Energy exchange strategy for local energy markets with heterogenous renewable sources. In Proceedings of the 2018 IEEE International Conference on Environment and Electrical Engineering and 2018 Industrial and Commercial Power Systems, Palermo, Italy, 12-15 June 2018.

2. Brautigam, A.; Rothacher, T.; Staubitz, H.; Trost, R. The Energy Storage Market in Germany; Germany Trade and Invest: Berlin, Germany, 2017.

3. De Martini, P.; Chandy, K.M.; Fromer, N.A. Grid 2020: Towards a Policy of Renewable and Distributed Energy Resources; Technical Report; California Institute of Technology, Resnick Institute: Pasadena, CA, USA, 2012.

4. Werth, A.; Kitamura, N.; Tanaka, K. Conceptual Study for Open Energy Systems: Distributed Energy Network Using Interconnected DC Nanogrids. IEEE Trans. Smart Grid 2015, 6, 1621-1630. [CrossRef]

5. Werth, A.; Andre, A.; Kawamoto, D.; Morita, T.; Tajima, S.; Tokoro, M.; Yanagidaira, D.; Tanaka, K. Peer-to-peer Control System for DC Microgrids. IEEE Trans. Smart Grid 2018, 9, 3667-3675. [CrossRef]

6. Asimakopoulou, G.E.; Dimeas, A.L.; Hatziargyriou, N.D. Leader-follower strategies for energy management of multi-microgrids. IEEE Trans. Smart Grid 2013, 4, 1909-1916. [CrossRef]

7. Wang, Z.; Chen, B.; Wang, J.; Begovic, M.M.; Chen, C. Coordinated energy management of networked microgrids in distribution systems. IEEE Trans. Smart Grid 2015, 6, 45-53. [CrossRef]

8. Matamoros, J.; Gregoratti, D.; Dohler, M. Microgrids energy trading in islanding mode. In Proceedings of the 2012 IEEE 3rd International Conference on Smart Grid Communications, SmartGridComm 2012, Tainan, Taiwan, 5-8 November 2012; pp. 49-54.

9. Gregoratti, D.; Matamoros, J. Distributed Energy Trading: The Multiple-Microgrid Case. IEEE Trans. Ind. Electron. 2015, 62, 2551-2559. [CrossRef]

10. Wang, H. Economic Mechanisms for Integrating Smart Grid Technologies into Power System. Ph.D. Thesis, The Chinese University of Hong Kong, Hong Kong, China, 2016.

11. Wang, H.; Huang, J. Bargaining-based energy trading market for interconnected microgrids. In Proceedings of the IEEE International Conference on Communications, London, UK, 8-12 June 2015; Volume 2015, pp. 776-781.

12. Wang, H.; Huang, J. Cooperative Planning of Renewable Generations for Interconnected Microgrids. IEEE Trans. Smart Grid 2016, 7, 2486-2496. [CrossRef] 
13. Zhang, L. Randomized Auction Design for Electricity Markets between Grids and Microgrids. ACM SIGMETRICS Perform. Eval. Rev. 2014, 42, 99-110. [CrossRef]

14. Saad, W.; Han, Z.; Poor, H.V. Coalitional game theory for cooperative micro-grid distribution networks. In Proceedings of the IEEE International Conference on Communications Workshops (ICC), Kyoto, Japan, 5-9 June 2011; pp. 6-10.

15. Nunna, H.S.V.S.K.; Doolla, S. Energy management in microgrids using demand response and distributed storage-A multiagent approach. IEEE Trans. Power Deliv. 2013, 28, 939-947. [CrossRef]

16. Dimeas, A.; Hatziargyriou, N. A multiagent system for microgrids. In Proceedings of the IEEE Power Engineering Society General Meeting, Denver, CO, USA, 6-10 June 2004; Volume 2, pp. 55-58.

17. Amato, A.; Martino, B.D.; Scialdone, M.; Venticinque, S. A Negotiation Solution for Smart Grid Using a Fully Decentralized, P2P Approach. In Proceedings of the 2015 Ninth International Conference on Complex, Intelligent, and Software Intensive Systems, Blumenau, Brazil, 8-10 July 2015; pp. 527-534.

18. Lagorse, J.; Paire, D.; Miraoui, A. A multi-agent system for energy management of distributed power sources. Renew. Energy 2010, 35, 174-182. [CrossRef]

19. Algarvio, H.; Lopes, F. Multi-agent Retail Energy Markets: Bilateral Contracting and Coalitions of End-use Customers. In Proceedings of the 12th International Conference on the European Energy Market (EEM), Lisbon, Portugal, 19-22 May 2015; p. 5.

20. Werth, A.; Kitamura, N.; Matsumoto, I.; Tanaka, K. Evaluation of centralized and distributed microgrid topologies and comparison to Open Energy Systems (OES). In Proceedings of the 15th International Conference on Environment and Electrical Engineering (EEEIC), Rome, Italy, 10-13 June 2015; pp. $492-497$.

(C) 2019 by the authors. Licensee MDPI, Basel, Switzerland. This article is an open access article distributed under the terms and conditions of the Creative Commons Attribution (CC BY) license (http:/ / creativecommons.org/licenses/by/4.0/). 